\title{
PENGARUH GAYA KEPEMIMPINAN KEPALA SEKOLAH TERHADAP KEDISIPLINAN GURU DI SEKOLAH MENENGAH KEJURUAN NEGERI 1 TANAH SEPENGGAL KABUPATEN BUNGO
}

\author{
Sugeng Kurniawan \\ Institut Agama Islam Yasni Bungo \\ Email: sugengkurniawan1982@gmail.com \\ Mela Putri Ayu \\ Mahasiswa Pascasarjana UIN Sulthan Thaha Saifuddin Jambi \\ Email: mellaputriayu28@gmail.com
}

\begin{abstract}
This research is a quantitative study with a correlational approach. This research designed to determine the effect to the principal leadership style to the discipline of teachers in State Vocational High School 1 Tanah Sepenggal District Bungo. The study population was teachers at SMK state 1 Tanah Sepenggal. The sample consisted of 30 people taken using Total Sampling techniques and the questionnaire was used as a research instrument. Research data werw analyzed using correlation analysis. The result of this study indicate that the discipline of teachers in the Vocational High School 1 Tanah Sepenggal District Bungo is strongly influenced by the principals leadership style that is equal to $8,29 \%$ at a high level of correlation coefficient and exceeds the significance value of $0.05 \%$ taken from the normally distributed population. The level of discipline of a teacher will increase if there is a good leadership style from the principal, because the teacher will emulate a leader. Based on data analysis and hypothesis testing, there is a positive and significant influence on the principal leadership style on the discipline of teacher in the State Vocational High School 1 Tanah Sepenggal District Bungo.
\end{abstract}

Keywords : leadership style, teacher discipline.

\begin{abstract}
Abstrak
Penelitian ini adalah penelitian kuantitatif dengan pendekatan korelasional. Tujuan penelitian ini adalah untuk mengetahui seberapa besar pengaruh yang ditimbulkan dari gaya kepemimpinan kepala sekolah terhadap kedisiplinan guru di Sekolah Menengah Kejuruan Negeri 1 Tanah Sepenggal Kabupaten Bungo. Populasi penelitian ini adalah guru di SMK Negeri 1 Tanah Sepenggal. Sampel terdiri dari 30 orang yang diambil dengan menggunakan teknik total sampling dan kuesioner digunakan sebagai instrumen penelitian. Data dari hasil penelitian dianalisis dengan menggunakan analisis korelasi. Hasil penelitian ini menunjukkan bahwa gaya kepemimpinan kepala sekolah dapat mempengaruhi kedisiplinan guru di Sekolah Menengah Kejuruan Negeri 1 Tanah Sepenggal Kabupaten Bungo dengan prosentase
\end{abstract}

Nur El-Islam, Volume 8, Nomor 1, April 2021 
pengaruhnya yaitu sebesar $8,29 \%$, artinya tingkat koefisien korelasinya tinggi dan melebihi nilai signifikansi sebesar $0.05 \%$ dan berdistribusi normal. Tingkat kedisiplinan seorang guru akan meningkat apabila ada gaya kepemimpinan yang baik dari kepala sekolah, karena guru akan meneladani seorang pemimpin. Berdasarkan analisis data dan pengujian hipotesis, ditemukan bahawa gaya kepemimpinan kepala sekolah memiliki pengaruh positif dan signifikan terhadap kedisiplinan guru di Sekolah Menengah Kejuruan Negeri 1 Tanah Sepenggal Kabupaten Bungo.

Kata kunci: gaya kepemimpinan, kedisiplinan guru.

\section{PENDAHULUAN}

Guru merupakan jabatan atau profesi yang memerlukan keahlian khusus sebagai guru. Pekerjaan ini tidak bisa dilakukan oleh orang yang tidak memiliki keahlian khusus guru. ${ }^{1}$ Guru harus berperan secara aktif dan menempatkan kedudukannya sebagai tenaga pendidik yang profesional, sesuai dengan bidangnya.

Guru dan kedisiplinan menjadi dua sisi mata koin yang tidak dapat dipisahkan. Tanpa kedisiplinan dalam melaksanakan tugas profesinya, maka tujuan mulia dari proses pembelajaran tidak akan pernah tercapai. Sesuai dengan perintah Allah dalam Al-Qur'an yang berbunyi:

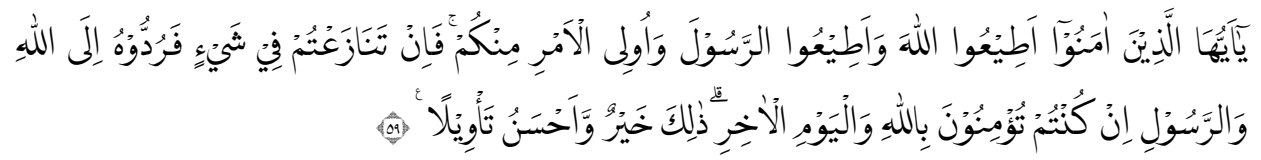

Artinya: “Wahai orang-orang yang beriman! Taatilah Allah dan taatilah Rasul (Muhammad), dan Ulil Amri (pemegang kekuasaan) di antara kamu. Kemudian, jika kamu berbeda pendapat tentang sesuatu, maka kembalikanlah kepada Allah (Al-Qur'an) dan Rasul (sunnahnya), jika kamu beriman kepada Allah dan hari kemudian. Yang demikian itu lebih utama (bagimu) dan lebih baik akibatnya. (Q.S. An-Nisa (4): 59)

\section{h. 23.}

${ }^{1}$ Jamil Suprihatiningrum, Guru Profesional, (Yogyakarta: Ar-Ruzz Media, 2016), 
Gaya kepemimpinan, pada dasarnya mengandung pengertian sebagai suatu perwujudan tingkah laku dari sesorang pemimpin yang menyangkut kemampuannya dalam memimpin. Seorang pemimpin harus memiliki komunikasi yang baik dengan guru, staf tata usaha dan lainnya agar terjadi keseimbangan dan keselarasan dalam menjalakan suatu organisasi dan apa yang menjadi visi dan misi organisai terlaksanakan dengan baik.

Perubahan lingkungan dalam suatu organisasi membutuhkan pemimpin yang tanggap perilaku yang dapat ditiru dengan baik serta gaya kepemimpinan yang khas akan memengaruhi bawahan. Gaya yang dimaksudkan sebagai cara berperilaku yang khas dari seorang pemimpin terhadap para anggota kelompoknya. Adapun indikator dari gaya kepemimpinan adalah seperti memberikan intruksi pada bawahan, mengambil keputusan, mengevaluasi, memberikan kesempatan kepada bawahan, bertanggung jawab, memotivasi, menjalin komunikasi dengan baik.

Undang-Undang Nomor 20 Tahun 2003 Bab XI pasal 39, menjelaskan bahwa tugas dari tenaga kependidikan apabila dilaksanakan dengan baik maka hasilnya pun akan baik, salah satunya yaitu dengan melaksanakan tugas pengawas yang terkait dengan pemimpin dan kepemimpinan, seperti yang kita tahu manusia di turunkan ke muka bumi sebagai khalifah makna khalifah itu sendiri merupakan pemimpin, jadi semua manusia adalah pemimpin baik memimpin orang lain maupun memimpin diri sendiri. ${ }^{2}$ Seperti yang terdapat dalam Al-Quran:

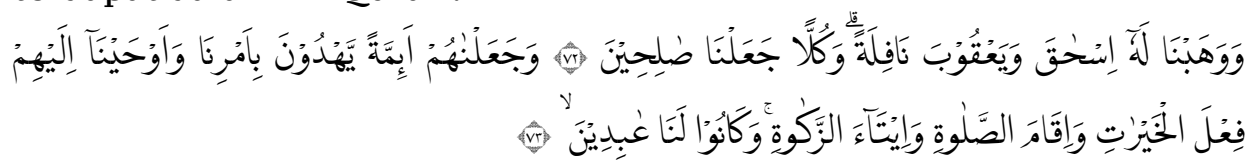

Artinya: Dan Kami menganugerahkan kepadanya (Ibrahim) Ishak dan Yakub, sebagai suatu anugerah. Dan masing-masing Kami jadikan orang yang saleh. Dan Kami menjadikan mereka itu sebagai pemimpin-pemimpin yang memberi petunjuk dengan

2 Peraturan Mentri Pendidikan Nasional No 20 Tahun 2003 Tentang Pendidik dan Tenaga Kependidikan (Jakarta: Lembaran Negara RI Tahun 2003, Nomor 20). 
perintah Kami dan Kami wahyukan kepada mereka agar berbuat kebaikan, melaksanakan salat dan menunaikan zakat, dan hanya kepada Kami mereka menyembah. (QS. Al-Anbiya: 72-73) $)^{3}$

Allah menyebutkan dalam ayat ini tambahan karunia-Nya kepada Ibrahim, selain karunia yang telah diterangkan pada ayat yang lalu, yaitu bahwa keturunan Ibrahim itu tidak hanya merupakan orang-orang yang saleh, bahkan juga menjadi imam atau pemimpin umat yang mengajak orang untuk menerima dan melaksanakan agama Allah, dan mengajak kepada perbuatan-perbuatan yang baik dan bermanfaat, berdasarkan perintah dan izin Allah.

Berdasarkan hasil penelitian awal diperoleh data tentang kedisiplinan guru. Masih terlihat guru yang belum disiplin dalam menjalankan tugasnya. Hal ini dapat diketahui ketika jam pelajaran sudah dimulai, guru masih berada di kantor. Kondisi seperti ini membuat siswa tidak tertib keluar masuk kelas, bahkan siswa melakukan hal-hal yang kurang etis seperti, memainkan ponsel, melempar kertas, naik ke atas meja bahkan kadang terjadi perkelahian.

Guru keluar dari kelas tidak sesuai dengan jam pelajarannya sebagaimana yang telah terjadwal dalam roster mengajar. Ini merupakan bukti bahwa kedisiplinan guru masih belum terlaksana dengan baik dalam melaksanakan tugasnya sebagai pendidik. Menurut peneliti ini ada kaitannya dengan gaya kepemimpinan kepala sekolah. Kepala sekolah seharusnya tanggap dengan kondisi yang terjadi pada bawahannya/guru. Kepala Sekolah harus memberikan sanksi pada guru yang melanggar aturan agar tidak terjadi hal-hal yang demikian.

Berdasarkan latar belakang masalah, maka dapat diidentifikasi masalah sebagai berikut:

1. Masih ada guru yang belum disiplin dalam kegiatan belajar mengajar.

\footnotetext{
${ }^{3}$ Kementrian Agama RI, Al-qur'an dan Terjemahannya, (Jawa Tengah: Penerbit Madina, 2016), h. 328.
} 
2. Masih ada guru yang belum memiliki motivasi sepenuhnya dalam mengajar.

3. Masih ada siswa yang belum memiliki motivasi belajar.

4. Gaya kepemimpinan kepala sekolah demokratis.

5.

\section{Kedisiplinan Guru}

Pengertian disiplin menurut bahasa, disiplin adalah tata tertib (di madrasah, kemiliteran dan sabagainya); ketaatan (kepatuhan) kepada peraturan tata tertib dan sebagainya. Sedangkan menurut Hadari Nabawi, disiplin diartikan bukan hanya sekedar pemberian hukuman atau paksaan agar setiap orang melaksanakan peraturan atau kehendak kelompok orang-orang tertentu. Sebagai pedoman Allah berfirman dalam Q.S. al-Ashr/103:1-3.

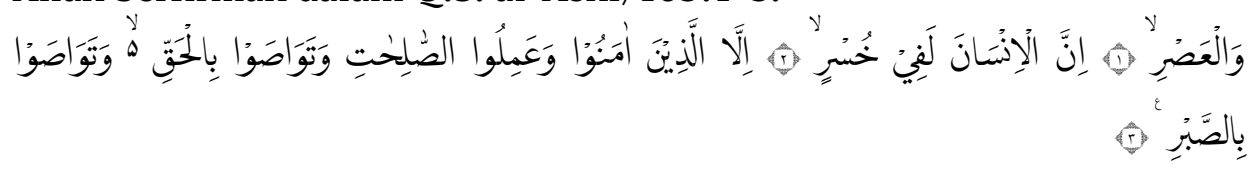

Artinya: "Demi masa, sungguh, manusia berada dalam kerugian,kecuali orang-orang yang beriman dan mengerjakan kebajikan serta saling menasihati untuk kebenaran dan saling menasihati untuk kesabaran". (Al'Asr/103:1-3) ${ }^{4}$

Menurut Depdiknas disiplin atau tertib ialah suatu sikap konsisten dalam melakukan sesuatu. Sedangkan guru ialah orang yang profesinya mengajar atau mendidik. Dalam UU Nomor 14 Tahun 2005 tentang Guru dan Dosen dinyatakan bahwa: Guru adalah pendidik profesional dengan tugas utama mendidik, mengajar, membimbing, mengarahkan, melatih, menilai, dan mengevaluasi peserta didik dan pendidikan anak usia dini jalur pendidikan formal, pendidikan dasar, dan pendidikan menengah. ${ }^{5}$ Guru adalah sosok yang digugu dan ditiru. Digugu artinya diindahkan atau dipercayai. Sedangkan ditiru artinya

\footnotetext{
${ }^{4}$ Kementrian Agama RI, Al-Quran dan Terjemahan, h. 601.

${ }^{5}$ UU Republik Indonesia No. 14 Tahun 2004, “Guru dan Dosen." http:/UUnomor-14-tahun-2004-ttg-guru-dan-dosen-pdf.Diakses pada tanggal 2 Maret 2019.
} 
dicontoh atau diikuti. Guru adalah profesi dimana seseorang menanamkan nilai-nilai kebajikan ke dalam jiwa manusia. ${ }^{6}$

Jadi kedisiplinan guru merupakan usaha yang dilakukan oleh tenaga pendidik dalam menaati tata tertib dan peraturan yang ada di suatu lembaga tertentu, disamping itu kedisiplinan seorang guru juga merupakan suatu bentuk ketaatan dan kepatuhan guru terhadap tata tertib yang berlaku.

Menurut Tabrani Rusyan disiplin mengandung ciri-ciri sebagai berikut:

1. Melaksanakan tata tertib dengan baik,baik bagi guru ataupun siswa karena tata tertib yang berlaku merupakan aturan dan ketentuan yang harus ditaati. Oleh siapapun demi kelancaran proses pendidikan tersebut yang meliputi:

2. Patuh terhadap aturan sekolah atau lembaga pendidikan

3. Mengindahkaan petunjuk-petunjuk yang berlaku di sekolah atau lembaga tertentu

4. Tidak membangkang pada peraturan berlaku

5. Tidak berbohong

6. Tingkah laku yang menyenangkan\

7. Rutin dalam mengajar

8. Tidak suka malas dalam mengajar tidak menyuruh orang untuk bekerja demi dirinya

9. Tepat waktu dalam belajar mengajar

10. Tidak pernah keluar dalam belajar mengajar

11. Tidak pernah membolos dalam belajar megajar

12. Taat terhadap kebijaksanaan yang berlaku ${ }^{7}$

Pendapat diatas dapat disimpulkan bahwa ciri-ciri guru disiplin yaitu guru yang datang tepat waktu, guru yang tidak korupsi dengan waktu pada proses belajar mengajar, dan guru yang patuh terhadap peraturan yang berlaku.

${ }^{6}$ Hamka Abdul Aziz, Karakter Guru Profesional (Jakarata: PT Al-Mawardi Prima, 2016), h. 19.

7 Tarbani Rusyan, Pendidikan Budi Pekerti (Bandung: PT Sinergi Pustaka Indonesia, 2006), h. 63. 


\section{Gaya Kepemimpinan}

Defenisi kepemimpinan terus mengalami perubahan sesuai dengan peran yang dijalankan, kemampuan untuk memperdaya (empowering) bawahan/anggota sehingga timbul inisiatif untuk berkreasi dalam bekerja dan hasilnya lebih bermakna bagi organisasi dengan sekali-kali pemimpin mengarahkan, menggerakkan, dan mempengaruhi anggotanya. ${ }^{8}$

Sedangkan Colquitt, LePine, dan Wesson mendefinisikan kepemimpinan sebagai penggunaan kekuasaan dan pengaruh untuk mengarahkan aktivitas pengikut ke arah pencapaian tujuan. Arah tersebut dapat mempengaruhi interpretasi kejadian pengikut, organisasi aktivitas pekerjaan mereka, komitmen mereka terhadap tujuan utama, hubungan mereka dengan pengikut, atau akses mereka pada kerja sama dan dukungan dari unit kerja lain. ${ }^{9}$

Kepemimpinan memiliki arti yang lebih dalam dari pada sekedar label atau jabatan yanag diberikan kepada seseorang manusia. Ada unsur visi jangka panjang serta karakter didalam sebuah kepemimpinan. ${ }^{10}$ Chermes mengemukakan kepemimpinan adalah suatu proses pengaruh sosial di mana seseorang bisa memeroleh bantuan dan dukungan dari orang lain dalam memenuhi suatu tugas umum. ${ }^{11}$

Kepemimpinan dipahami sebagai segala daya dan upaya untuk menggerakkan semua sumber dan alat (resources) di dalam suatu organisasi. Untuk itu sukses atau tidaknya suatu organisasi tergantu kemampuan pemimpin mengelola dan menggerakkan sumber-sumber

${ }^{8}$ Wahyudi, Kepemimpinan Kepala Sekolah Dalam Organisasi Pembelajar, (Pontianak: Alfabeta, 2009), h. 119

${ }^{9}$ Jason A. Colquitt, J. Lepine, Michael J. Wessom, Organizational Behavior Improving Performance and Commitment in the Workplace, (USA: McGraw-Hill Education, 2015), h. 483.

${ }^{10}$ Tikno Lensufiie, Leadership untuk Profesional dan Mahasiswa (Jakarta: Erlangga,2010), h. 2.

${ }^{11}$ Ibid.,h. 53. 
tersebut. Sehingga dapat memperdaya dan dapat berjalan secara efektif dan efisien. ${ }^{12}$

Sebagai pedoman Allah berfirman dalam Q.S Al-Maaidah ayat 57:

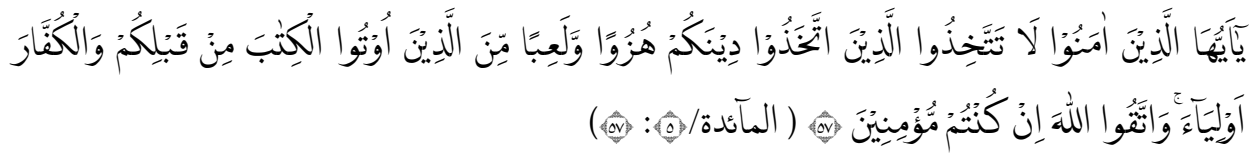

Artinya: Wahai orang-orang yang beriman! Janganlah kamu menjadikan pemimpinmu orang-orang yang membuat agamamu jadi bahan ejekan dan permainan, (yaitu) di antara orang-orang yang telah diberi kitab sebelummu dan orangorang kafir (orang musyrik). Dan bertakwalah kepada Allah jika kamu orang-orang beriman. (Al-Ma'idah/5:57)

Seorang pemimpin dalam lembaga pendidikan Islam hendaknya mempunyai pengaruh yang dapat memerintah dan mencegah. Karena pemimpin harus memberikan pengawasan kepada bawahannya, meluruskan kekeliruan, serta mengajak mereka untuk berbuat kebaikan dan mencegah kemungkaran dengan cara bermusyawarah dengan bawahannya serta meminta pendapat dan pengalaman mereka. Dengan melakukan hal demikian ini menunjukkan bahwa seorang pemimpin tersebut telah memfungsikan keistimewaannya dibandingkan dengan yang lainnya. Sebagaimana firman Allah Swt.

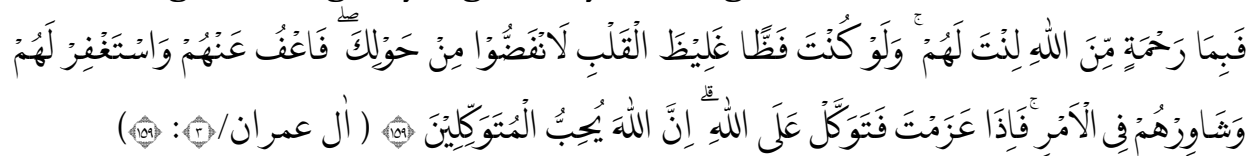

Artinya: "Maka disebabkan rahmat dari Allah-lah kamu berlaku lemah lembut terhadap mereka. Sekiranya kamu bersikap keras lagi berhati kasar, tentulah mereka menjauhkan diri dari sekelilingmu. karena itu ma'afkanlah mereka, mohonkanlah ampun bagi mereka, dan bermusyawaratlah dengan mereka

${ }^{12}$ Marno dan Triyo Supriyatno, Manajemen dan Kepemimpinan Pendidikan Islam (Bandung: PT Refika Aditama, 2008), h. 29-30. 
dalam urusan itu, kemudian apabila kamu telah membulatkan tekad, maka bertawakkallah kepada Allah. Sesungguhnya Allah menyukai orang-orang yang bertawakkal kepada-Nya (Q.S. Ali Imran/3:159). ${ }^{13}$

Menurut Ibn Katsir di dalam tafsirnya al-Qur'a>n al-'Ad\}i>m, sikap lemah lembut yang dimiliki oleh nabi Muhammad SAW itu tiada lain disebabkan karena rahmat Allah yang dianugrahkan kepadanya, sehingga beliau bersikap lemah lembut terhadap mereka. Demikian juga $A l-H$ asan Al-Bas\}ri mengatakan bahwa begitulah akhlak nabi Muhammad SAW yang diutus oleh Allah. Kemudian ayat selanjutnya mengatakan: "dan jikalau kamu bersikap keras dan berhati kasar tentulah mereka akan menjauh darimu”. Artinya adalah sekiranya kamu kasar dalam berbicara dan berkeras hati dalam menghadapi mereka, niscaya mereka bubar darimu dan meninggalkanmu. ${ }^{14}$

Gaya kepemimpinan dapat diartikan sebagai sesuatu pola yang dilakukan oleh para pemimpin, yaitu proses di mana para pemimpin menggunakan pengaruhnya untuk memperjelas tujuan organisasi bagi para pegawai, bawahan, atau yang dipimpinnnya, memotivasi mereka untuk mencapai tujuan tersebut, serta membantu menciptakan suatu budaya produktif dalam organisasi. ${ }^{15}$

Gaya kepemimpinan merupakan pola perilaku seorang pemimpin yang khas pada saat mempengaruhi anak buahnya. Untuk memahami gaya kepemimpinan setidaknya dapat dikaji dari tiga pendekatan yaitu pendekatan sifat, pendekatan perilaku dan pendekatan situasional. ${ }^{16}$ Penjelasan diatas dapat disimpulkan bahwa makna dari gaya kepemimpinan ialah suatu sikap dan tata cara yang sudah terbiasa dari seseorang dalam memimpin suatu organisasi .

${ }^{13}$ Ibid., hal. 72

${ }^{14}$ Imam Abdul Fida Isma'il Ibnu Kasit Ad-Dimasyqi, Tafsir Ibnu Katsir, terjemahan. Bahrun Abu Bakar (Bandung: Sinar Baru Algesindo, 2009), h. 244-251.

${ }^{15}$ Suwatno dan Donni Juni Priansa, Manajemen SDM dalam Organisasi Publikasi dan Bisnis, (Bandung: Alfabeta, 2013), h. 140-141.

${ }^{16}$ E. Mulyasa, Manajemen Berbasis Sekolah Konsep Strategi dan Implementasi (Bandung: Remaja Rosdakarya, 2012), h. 108. 


\section{Hipotesis Penelitian}

Hipotesis (hypothesis) berasal dari bahasa Yunani, Hupo = sementara ; dan Thesis = pernyataan atau dugaan. ${ }^{17}$ Hipotesis juga menjadi kendali bagi seorang peneliti agar arah penelitian sesuai dengan tujuan penelitiannya. ${ }^{18}$ Adapun hipotesis penelitian ini adalah: Gaya kepemimpinan kepala sekolah berpengaruh langsung positif terhadap kedisiplinan guru di Sekolah Menengah Kejuruan Negeri 1 Tanah Sepenggal.

Hipotesis statistik pada penelitian ini ada dua diantarnya :

$\mathrm{H}_{1}$ : tidak ada pengaruh gaya kepemimpinan kepala sekolah terhadap kedisiplinan guru

$\mathrm{H}_{\mathrm{o}}$ : ada pengaruh gaya kepemimpinan terhadap kedisiplinan guru

\section{METODOLOGI PENELITIAN}

Pendekatan penelitian ini merupakan penelitian kuantitatif korelasional. Dengan menggunakan metode survei yang melihat pengaruh antara satu atau lebih dengan yang lainnya. Penilitian ini menganalisis pengeruh veriabel $\mathrm{X}$ terhadap veriabel $\mathrm{Y}$ dengan menggunakan pendekatan analisis korelasi.

Populasi dalam penelitian ini adalah seluruh guru yang ada di Sekolah Menengah Kejuruan Negeri 1 Tanah Sepenggal dengan kriteria guru Pegawai Negeri Sipil (PNS) sebanyak 11 orang dan guru honorer sebnyak 19 orang.

Sample (contoh) adalah sebagian anggota populasi yang diambil dengan menggunakan teknik tertentu yang disebut dengan teknik Probability Sampling. ${ }^{19}$ Probability sampling adalah teknik pengambilan sampel yang memberikan peluang yang sama bagi setiap unsur (anggota) populasi untuk dipilih menjadi anggota sampel. ${ }^{20}$

${ }^{17}$ Ating Somantri dan Sambas Ali Muhidin, Aplikasi Statistika Dalam Penelitian, (Bandung: CV Pustaka Setia, 2006), h. 157.

${ }^{18}$ Subana,Moersetyo Rahadi dan Sudrajat, Statistika Pendidikan, (Bandung: CV Pustaka Setia, 2000), h. 112.

${ }^{19}$ Ibid., h.182.

${ }^{20}$ Sugiyono, Metode Penelitian Kuantitatif, Kualitatif dan $R \& D$ (Bandung: Alfabeta, 2013), h. 82 
Sampel dalam penelitian ini adalah seluruh populasi, karena jumlah populasinya adalah kurang dari 100 orang.

Instrumen yang digunakan dalam penelitian ini adalah angket (kuesioner). Angket atau kuesioner adalah instrument pengumpulan data yang digunakan dalam teknik komunikasi tak langsung, artinya responden secara tidak langsung menjawab daftar pertanyaan tertulis yang dikirim melalui media tertentu. ${ }^{21}$ Pertanyaan-pertanyaan dalam angket tersebut disusun menggunakan skala likert (digunakan untuk mengukur sikap seseorang). Setiap pertanyaan dari masing-masing item memiliki lima alternatif jawaban dengan bobot $1 \mathrm{~s} / \mathrm{d} 5$.

Untuk menguji validitas instrumen penelitian peneliti menggunakan rumus product moment, dengan rumus: $:^{22}$

$r_{x y}=\frac{N \sum x y-\left(\sum x\right)\left(\sum y\right)}{\sqrt{\left(N \sum x^{2}-\left(\sum x\right)^{2}\left(N \sum y^{2}-\left(\sum y\right)^{2)}\right.\right.}}$

\section{Keterangan:}

$\mathrm{r}_{\mathrm{xy}} \quad=$ Koefisien Korelasi antara $\mathrm{x}$ dan $\mathrm{y}$

$\mathrm{N} \quad=$ Jumlah subjek

$\sum \mathrm{xy} \quad=$ Jumlah perkalian antara skor $\mathrm{x}$ dan skor $\mathrm{y}$

$\mathrm{x}=$ Jumlah total skor $\mathrm{x}$

$\mathrm{y} \quad=$ Jumlah total skor $\mathrm{y}$

$\mathrm{x}^{2} \quad=$ Jumlah dari kuadrat $\mathrm{x}$

$\mathrm{y}^{2} \quad=$ Jumlah dari kuadrat $\mathrm{y}$

Untuk mengetahui valid atau tidaknya sebuah instrumen penelitian, maka nilai $r_{\text {hitung }}$ dibandingkan dengan $r_{\text {tabel. }}$ Jika nilai $r_{\text {hitung }}$ lebih besar dari $r_{\text {tabel }}$ maka instrument dinyatakan valid, begitupun sebaliknya. Uji validitas instrumen ini menggunakan rumus SPSS 20.

Selain uji validitas instrument, penelitian ini juga menggunakan uji reliabilitas instrument. Pada penelitian ini peneliti menggunakan rumus Alpha Crombach. Adapun rumusnya adalah sebagai berikut: ${ }^{23}$

${ }^{21}$ Subana dan Moersetyo Rahadi, Statistik Pendidikan. h. 30.

${ }^{22}$ Misbahuddin dan Iqbal Hasan, Analisis Data Penelitian dengan Statistik (Jakarta: PT Bumi Aksara, 2013), h. 66.

${ }^{23}$ Ibid., h. 301. 
$r 11=\left(\frac{n}{n-1}\right)\left(1-\frac{\sum s i 2}{\sum s t 2}\right)$

Keterangan:

$r 11=$ Koefisien reliabilitas tes

$\mathrm{n} \quad=$ Banyaknya butir item yang dikeluarkan dalam tes

$1=$ Konstanta

$\sum S_{I}^{2}=$ Jumlah varian skor dari tiap-tiap butir item

$\sum \mathrm{S}_{\mathrm{t}}{ }^{2}=$ Varian total

Uji realibilitas instrumen dalam penelitian ini menggunakan SPSS 20. Untuk mengetahui tinggi rendahnya koefisien realibilitas. Apabila $r_{\text {hitung }}<r_{\text {tabel }}$ dengan taraf signifikan 0,05 maka instrument realibel begitu pula sebaliknya jika $r_{\text {hitung }}>r_{\text {tabel }}$ maka instrument tidak realibel.

Pada penelitian ini peneliti menggunakan teknik Analisis Deskriptif. Analisis Deskriftif adalah statistik yang digunakan untuk menganalisis data dengan cara mendeskripsikan atau menggambarkan data yang telah terkumpul sebagaimana adanya tanpa bermaksud membuat kesimpulan untuk umum atau generalisasi. Statistik deskriptif dapat digunakan bila peneliti hanya ingin mendeskripsikan data sampel, dan tidak ingin membuat kesimpulan yang berlaku untuk populasi dimana sampel diambil.

Uji persyaratan analisis dalam penelitian ini menggunakan uji normalitas, uji homogenitas dan uji linearitas regresi.

Uji normalitas data adalah uji prasyarat tentang kelayakan data untuk dianalisis dengan menggunakan statistis nonparametik. Melalui uji ini, sebuah data hasil penelitian dapat diketahui bentuk distribusi data tersebut, yaitu berdistribusi normal atau tidak normal. Sebelum menganalisis data, maka data dari tes harus diuji normalitasnya dengan menggunakan uji Kolmogrov-Smirnov. Uji kolmogrov-smirnov adalah uji normalitas dengan menggunakan aturan kolmogrovsmirnov.

Uji homogenitas data adalah uji persyaratan analisis tentang kelayakan data untuk dianalisis dengan menggunakan uji statistik tertentu. Sebelum menganalisis data, maka data dari tes harus di uji 
dengan uji homogenitas Perbandingan Varians. Perbandingan varians dengan menggunakan rumus sebagai berikut:

$\mathrm{F}_{0}=\frac{\text { varians terbesar }}{\text { varians terkecil }}$

Uji linearitas merupakan uji prasyarat analisis untuk mengetahui pola data, apakah data berpola linier atau tidak. Uji ini berkaitan dengan pengunaan regresi linear. Jika akan menggunakan jenis regresi linear, maka datanya harus menunjukkan pola (diagram) yang berbentuk linear (lurus). Jika akan menggunakan jenis regresi nonlinear, maka datanya tidak perlu menunjukkan pola linear. Uji linearitas pada penelitian ini menggunakan analisis varians (Anova).

\section{PEMBAHASAN}

Penelitian ini dilaksanakan dari tanggal 16 Mei - 10 Agustus tahun 2019. Pelaksanaan penelitian di awali dengan menjumpai kepala sekolah untuk menyerahkan surat penelitian dari Institut Agama Islam Yasni Bungo untuk mendapatkan izin penelitian. Observasi sebelumnya sudah dilakukan sebelum peneliti menyebarkan angket. Sistematika yang di lakukan peneliti yaitu :

\section{Uji Normalitas}

Uji normalitas digunakan untuk mengetahui bahwa populasi berasal dari data yang berdistribusi normal dengan menggunakan uji Kolmogrov-Smirnov. Uji normalitas data dengan menggunakan rumus Kolmogrov-Smirnov $\mathrm{A}_{\text {hitung }}=\mathrm{MAX}|\mathrm{F}(\mathrm{z})-\mathrm{S}(\mathrm{z})|$. Uji normalitas di lakukan pada variable $\mathrm{X}$ dan $\mathrm{Y}$ dengan jumlah peserta 30 orang guru.

\section{Uji Normalitas Variabel Kedisiplinan Guru (Y)}

Perumusan hipotesis yang akan diuji sebagai berikut:

$\mathrm{H}_{\mathrm{o}}=$ Sampel berasal dari populasi yang berdistribusi normal $\mathrm{H}_{\mathrm{a}}=$ Sampel berasal dari populasi yang tidak berdistribusi normal

Adapun kriteria pengujian adalah sebagai berikut:

$\mathrm{H}_{\mathrm{o}}=$ Diterima apabila $A_{\text {hitung }}>\mathrm{A}_{\text {tabel }}$

$\mathrm{H}_{\mathrm{o}}=$ Ditolak apabila $A_{\text {hitung }}<\mathrm{A}_{\text {tabel }}$ 
Uji normalitas variabel kedisiplinan guru (Y) dengan perhitungan statistik secara manual diperoleh hasil sebagaimana berikut :

Diketahui:

$\mathrm{N}=30$ ( Banyak Sampel)

$\alpha=0,05$ atau $5 \%$ Signifikansi

Tabel Uji Normalitas Variabel Kedisiplinan Guru

\begin{tabular}{|c|c|c|c|c|c|c|c|c|}
\hline No & Y & F & Y.F & S(y) & Z & F(y) & F(y)-S(y) & $\left(\mathrm{Y}-\bar{Y}^{2}\right.$ \\
\hline 1 & 58 & 3 & 174 & 0,1 & $-0,4216$ & 0,3366 & 0,236 & 3,72 \\
\hline 2 & 60 & 4 & 240 & 0,23 & 0,0145 & 0,5058 & 0,2758 & 0,00 \\
\hline 3 & 61 & 2 & 122 & 0,3 & 0,2326 & 0,5919 & 0,2919 & 1,1449 \\
\hline 4 & 62 & 2 & 124 & 0,37 & 0,4506 & 0,6738 & 0,3038 & 4,2849 \\
\hline 5 & 63 & 6 & 378 & 0,57 & 0,6687 & 0,7481 & 0,1781 & 9,4249 \\
\hline 6 & 65 & $\mathrm{M}$ & 390 & 0,76 & 1,1048 & 0,8653 & 0,1053 & 25,7049 \\
\hline 7 & 50 & 2 & 100 & 0,83 & $-2,1661$ & 0,0151 & 0,8149 & 98,6049 \\
\hline 8 & 55 & 2 & 110 & 0,9 & $-1,0758$ & 0,1410 & 0,759 & 24,3049 \\
\hline 9 & 53 & 2 & 106 & 0,97 & $-1,5119$ & 0,0652 & 0,9048 & 48,0249 \\
\hline 10 & 54 & 1 & 54 & 1 & $-1,2938$ & 0,0978 & 0,9022 & 35,1649 \\
\hline JML & & 30 & 1798 & & & & & \\
\hline
\end{tabular}

Mean $(\mathrm{Y})=\frac{\text { Jumlah Semua Data }}{\mathrm{N}(\text { Banyaknya Sampel })}=\frac{1798}{30}=59,93$

Standar Deviasi $(\mathrm{S})=\frac{\Sigma(\mathrm{Y}-\overline{\mathrm{Y}})^{2}}{\mathrm{~N}}$ maka di dapatkan hasil 4,58

$\mathrm{Z}=\frac{\mathrm{Y}-\overline{\mathrm{Y}}}{\mathrm{S}}=\frac{58-59,93}{4,58}=0,4216$ (dan seterusnya)

\section{Uji Normalitas Variabel Gaya Kepemimpinan (X)}

Uji normalitas variabel gaya kepemimpinan (X) dengan perhitungan statistik secara manual diperoleh hasil sebagaimana berikut :

Diketahui:

$\mathrm{N}=30$ ( Banyak Sampel)

$\alpha=0,05$ atau $5 \%$ Signifikansi

Tabel Uji Normalitas Variabel Gaya Kepemimpinan 
Pengaruh Gaya Kepemimpinan ...

\begin{tabular}{|c|c|c|c|c|c|c|c|c|}
\hline No & $\mathbf{X}$ & $\mathbf{F}$ & $\mathbf{X . F}$ & $\mathrm{S}(\mathbf{X})$ & $\mathbf{Z}$ & $\mathbf{F}(\mathbf{X})$ & $\begin{array}{c}F(\mathbf{x})- \\
\text { S(x) }\end{array}$ & $(\mathbf{X}-\mathbf{X})^{2}$ \\
\hline 1 & 43 & 1 & 43 & 0,03 & 0,8820 & 0,811121 & 0,7811 & 20,8849 \\
\hline 2 & 30 & 2 & 60 & 0,1 & $-1,62887$ & 0,051671 & 0,0484 & 71,0649 \\
\hline 3 & 34 & 3 & 102 & 0,2 & $-0,85628$ & 0,195921 & 0,0041 & 19,6249 \\
\hline 4 & 40 & 6 & 240 & 0,4 & 0,302596 & 0,618901 & 0,2189 & 2,4649 \\
\hline 5 & 44 & 1 & 44 & 0,43 & 1,07518 & 0,858853 & 0,4288 & 31,0249 \\
\hline 6 & 45 & 6 & 270 & 0,63 & 1,268326 & 0,897659 & 0,2676 & 43,1649 \\
\hline 7 & 32 & 1 & 32 & 0,67 & $-1,24257$ & 0,107013 & 0,563 & 12,86 \\
\hline 8 & 42 & 2 & 84 & 0,73 & 0,688888 & 0,754553 & 0,0245 & 12,7449 \\
\hline 9 & 37 & 3 & 111 & 0,83 & $-0,27684$ & 0,39095 & 0,4391 & 2,0449 \\
\hline 10 & 31 & 3 & 93 & 0,93 & $-1,43572$ & 0,075541 & 0,8525 & 55,2049 \\
\hline 11 & 35 & 1 & 35 & 0,97 & $-0,66314$ & 0,253622 & 0,7164 & 11,7649 \\
\hline 12 & 39 & 1 & 39 & 1 & 0,109449 & 0,543577 & 0,4565 & 0,3249 \\
\hline JML & & 30 & 1798 & & & & & \\
\hline
\end{tabular}

Mean $(X)=\frac{\text { Jumlah Semua Data }}{\mathrm{N}(\text { Banyaknya Sampel })}=\frac{1153}{30}=38,43$

Standar Deviasi $(S)=\frac{\Sigma(\mathrm{X}-\overline{\mathrm{X}})^{2}}{\mathrm{~N}}$ maka di dapatkan hasil 5,17

$\mathrm{Z}=\frac{\mathrm{X}-\overline{\mathrm{X}}}{\mathrm{S}}=\frac{43-38,43}{5,17}=0,8820$ (dan seterusnya).

Tabel Rekapitulasi Uji Normalitas

\begin{tabular}{|c|c|c|c|c|c|}
\hline Variable & $\mathbf{N}$ & $\begin{array}{c}\text { Rata- } \\
\text { rata }\end{array}$ & $\mathbf{A}_{\text {hitung }}$ & $\mathbf{A}_{\text {tabel }}$ & Keputusan \\
\hline $\begin{array}{c}\text { Gaya } \\
\text { Kepemimpinan }\end{array}$ & 30 & 38,43 & 0,8525 & 0,242 & $\mathrm{H}_{\mathrm{o}}$ di terima \\
\hline Kedisiplinan Guru & 30 & 59.93 & 0,9048 & 0,242 & $\mathrm{H}_{\mathrm{o}}$ di terima \\
\hline Syarat : & \multicolumn{6}{|}{$\begin{array}{c}\mathrm{H}_{\mathrm{o}} \text { diterima apabila } \mathrm{A}_{\text {hitung }}>\mathrm{A}_{\text {tabel }} \\
\mathrm{H}_{\mathrm{o}} \text { ditolak apabila } \mathrm{A}_{\text {hitung }}<\mathrm{A}_{\text {tabel }}\end{array}$} \\
\hline
\end{tabular}

Pada tabel 9, dapat dilihat bahwa uji normalitas yang terdapat pada variabel gaya kepemimpinan dengan jumlah guru 30 orang, 
memperoleh nilai rata-rata yaitu 38,43. A Aitung $=\operatorname{MAX}|\mathrm{F}(\mathrm{z})-\mathrm{S}(\mathrm{z})|$ memperoleh nilai yaitu 0,8525 dengan $A_{\text {tabel }}$ yaitu 0,242 maka dari data tersebut $A_{\text {hitung }}>A_{\text {tabel }}(0,8528>0.242)$. Disimpulkan $\mathrm{H}_{\mathrm{o}}$ diterima data berdistribusi normal.

Variabel kedisiplinan guru dengan jumlah responden 30 orang, memperoleh nilai rata-rata 59.93. $A_{\text {hitung }}=\mathrm{MAX}|\mathrm{F}(\mathrm{z})-\mathrm{S}(\mathrm{z})|$ dengan nilai 0,9048 dengan $A_{\text {tabel }}$ yaitu 0,242 maka data tersebut $A_{\text {hitung }}>A_{\text {tabel }}$ $(0,9048<0,242)$. Maka dapat disimpulkan $H_{0}$ diterima dan data berdistribusi normal.

\section{Uji Homogenitas}

Uji homogenitas dalam penelitian ini, menggunakan uji varians terbesar dibagi varians terkecil. Pada penelitian ini peneliti membandingkan dua variabel yaitu variabel gaya kepemimpinan dan kedisiplinan guru dengan cara varians terbesar dibagi varians terkecil, dengan perumusan hipotesis sebagai berikut:

$\mathrm{H}_{\mathrm{o}}=$ Data varians homogen

$\mathrm{H}_{1}=$ Data tidak varians homogen

Kriteria dalam pengujian ini adalah sebagai berikut:

$\mathrm{H}_{\mathrm{o}}=$ Diterima apabila $\mathrm{F}_{\text {hitung }}<\mathrm{F}_{\text {tabel }}$

$\mathrm{H}_{1}=$ Ditolak apabila $\mathrm{F}_{\text {hitung }}>\mathrm{F}_{\text {tabel }}$

Diketahui :

$\mathrm{N}=30$

$\alpha=0,05$ atau $5 \%$ signifikansi

\section{Uji homogentitas untuk variabel $\mathrm{X}$}

$$
\begin{aligned}
& S \mathrm{X}^{2}=\sqrt{\frac{N \cdot \Sigma x^{2}-\Sigma(x)^{2}}{N-(N-1)}}=\sqrt{\frac{30.45091-(1153)^{2}}{30-(30-1)}}=\sqrt{\frac{1352730-1329409}{30(29)}} \\
& =\sqrt{\frac{23321}{870}}=\sqrt{26,80}=5,17
\end{aligned}
$$

\section{Uji homogentitas untuk variabel Y}

$$
\begin{aligned}
& S y^{2}=\sqrt{\frac{N \cdot \Sigma y^{2}-\Sigma(y)^{2}}{N-(N-1)}}=\sqrt{\frac{30.108370-(1798)^{2}}{30-(30-1)}}=\sqrt{\frac{3251100-3232804}{30(29)}} \\
& =\sqrt{\frac{18296}{870}}=\sqrt{21,02}=4,58
\end{aligned}
$$


$\mathrm{F}=\frac{\text { varians terbesar }}{\text { varians terkecil }}=\frac{5,17}{4,58}=1,12$

Uji homogenitas varians didapatkan nilai varians terbesar adalah 5,27 dan varian terkecil 4,58 dengan demikian perbandingan varians diperoleh nilai 1,12 dan hasilnya dinyatakan homogen karena nilai $F_{\text {hitung }}$ lebih kecil dari $F_{\text {tabel }}(1,12<1,85)$, maka data bervarians sama atau homogen.

\section{Uji Liniearitas}

Linieritas merupakan uji pra syarat apakah pola data linier atau tidak. Pada penelitian ini peneliti menguji linieritas antara variabel $\mathrm{X}$ dan Y. Untuk mengetahui apakah ada pengaruh gaya kepemimpinan kepala sekolah terhadap kedisiplinan guru.

Tabel Uji Linearitas Variabel X terhadap Y

\begin{tabular}{|c|c|c|c|c|c|}
\hline \multirow{2}{*}{ No } & $\begin{array}{c}\text { Gaya } \\
\text { Kepemimpinan }\end{array}$ & $\begin{array}{c}\text { Kedisiplinan } \\
\text { Guru }\end{array}$ & $\mathrm{X}^{2}$ & $\mathrm{Y}^{2}$ & $\mathrm{X} . \mathrm{Y}$ \\
\hline \multirow{2}{*}{$\Sigma$} & $\mathrm{X}$ & $\mathrm{Y}$ & \multirow{2}{*}{1329409} & 3232804 & 2073094 \\
\cline { 2 - 3 } & 1153 & 1798 & & \\
\hline
\end{tabular}

\section{Keterangan :}

$\mathrm{N}$

$(\Sigma \mathrm{x}) \quad=1153$

$(\Sigma \mathrm{x})^{2}=1329409$

$(\Sigma \mathrm{y})^{2}=3232804$

$(\Sigma x . y)=2073094$

$\mathrm{a}=\frac{(\Sigma \mathrm{y})\left(\Sigma x^{2}\right)-(\Sigma \mathrm{x})(\mathrm{xy})}{n \Sigma x^{2}-(\Sigma x)^{2}}=\frac{(1798)(1329409)-(1153)(2073094)}{30\left(1329409-(1153)^{2}\right.}=0$

$\mathrm{b}=\frac{\mathrm{n} \cdot(\Sigma \mathrm{xy})-(\Sigma \mathrm{x})(\Sigma \mathrm{y})}{n\left(\Sigma x^{2}\right)-(\Sigma x)^{2}}==\frac{30 \cdot(2073094)-(1153)(1798)}{30(1329409)-(1153)^{2}}=1,55$

$\mathrm{Y}=\mathrm{a}+\mathrm{bX}=0+1,55 \mathrm{X}$

$\mathrm{JK}_{\text {reg (a) }}=107760,13$

$\mathrm{JK}_{\mathrm{t}}=3232804$

$\mathrm{JK}_{\mathrm{reg}(\mathrm{b} / \mathrm{a})}=\mathrm{b}\left(\Sigma \mathrm{xy}-\frac{\Sigma \mathrm{x} . \Sigma \mathrm{y}}{n}\right)=1,55.2073094-\frac{1153.1798}{30}=3106185,8$

$\mathrm{JK}_{\text {res }}=\Sigma \mathrm{y}^{2}-\mathrm{JK}_{\mathrm{reg}(\mathrm{b} / \mathrm{a})-} \mathrm{JK}_{\mathrm{reg}(\mathrm{a})}=3232804-3106185,8-107760,13=$ 18858,07 


$$
\mathrm{RJK}_{\text {reg (a) }}=\mathrm{JK}_{\text {reg (a) }}=107760,13
$$

$\mathrm{RJK}_{\mathrm{reg}(\mathrm{b} / \mathrm{a})}=\mathrm{JK}_{\mathrm{reg}(\mathrm{b} / \mathrm{a})}=3106185,8$

$\mathrm{RJK}_{\text {res }}=\frac{\mathrm{JKres}}{n-2}=\frac{18858,07}{30-2}=673.5052$

$\mathrm{JK}_{\mathrm{e}}=\Sigma_{\mathrm{k}}\left[\Sigma Y^{2} \frac{\Sigma Y^{2}}{N}\right]=28567,5$

$\mathrm{RJK}_{\mathrm{tc}}=\frac{\mathrm{JKtc}}{k-2}=2754,56$

$\mathrm{RJK}_{\mathrm{e}}=\frac{\mathrm{JKe}}{n-k}=\frac{28567,5}{30-22}=1020,26$

$\mathrm{Uji} \mathrm{F}=\frac{\mathrm{RJKtc}}{\text { RJKe}}=\frac{2754,56}{1020,26}=2,69$

\begin{tabular}{|c|c|c|c|c|c|c|c|}
\hline \multicolumn{8}{|c|}{ Tabel Anova } \\
\hline $\begin{array}{l}\text { Sumber } \\
\text { variabel }\end{array}$ & $\begin{array}{l}d \\
b\end{array}$ & JK & RJK & $\begin{array}{c}F_{\text {hitun }} \\
g\end{array}$ & $\begin{array}{c}F_{\text {tabe }} \\
1 \\
\alpha= \\
0,0 \\
5\end{array}$ & $\begin{array}{c}\mathbf{F}_{\text {tabe }} \\
1 \\
\alpha= \\
0,0 \\
1\end{array}$ & Ket \\
\hline Total & 30 & 3232804 & & & & & \\
\hline $\begin{array}{l}\text { Koefisie } \\
\text { n (a) }\end{array}$ & 1 & $\begin{array}{l}107760,1 \\
3\end{array}$ & $\begin{array}{l}107760,1 \\
3\end{array}$ & & & & \\
\hline $\begin{array}{l}\text { Regresi } \\
\text { (b/a) }\end{array}$ & 1 & $\begin{array}{l}3106185, \\
8\end{array}$ & $\begin{array}{l}3106185, \\
8\end{array}$ & 0 & $\begin{array}{c}4,2 \\
0\end{array}$ & $\begin{array}{c}7,6 \\
4\end{array}$ & $\begin{array}{l}\text { Signifika } \\
\mathrm{n}\end{array}$ \\
\hline Sisa & 28 & 18858,07 & 673.5052 & & & & \\
\hline $\begin{array}{l}\text { Tuna } \\
\text { cocok }\end{array}$ & 10 & 23756,45 & 2754,56 & 2,69 & $\begin{array}{c}2,1 \\
9\end{array}$ & $\begin{array}{c}3,0 \\
7\end{array}$ & Linier \\
\hline Galat & 18 & 28567,5 & 1020,26 & & & & \\
\hline
\end{tabular}

Berdasarkan tabel diatas, $F_{\text {hitung }}=2,69$ dan $F_{\text {tabel }}=2,19$ maka $F_{\text {hitung }}$ $>\mathrm{F}_{\text {tabel }}$ dapat disimpulkan antara variabel $\mathrm{X}$ dan $\mathrm{Y}$ adalah linier. Pengujian ini menggunakan program SPSS 20 dengan pengambilan dasar keputusan sebagai berikut:

Membandingkan nilai signifikan (Sig.) dengan taraf signifikansi 0,05

1. Jika nilai Deviation from Linearity Sig. $>0,05$ maka ada pengaruh yang linier secara signifikan.

2. Jika nilai Deviation from Linearity Sig. < 0,05 maka tidak ada pengaruh yang linier secara signifikan. 
Hipotesis uji linieritas ini adalah sebagai berikut:

1. $\mathrm{H}_{0}$ : terdapat pengaruh antara gaya kepemimpinan terhadap kedisiplinan guru.

2. $\mathrm{H}_{1}$ : tidak terdapat pengaruh anatar gaya kepemimpinan kepala sekolah terhadap

kedisiplinan guru.

Berdasarkan tabel di atas maka dapat dilihat bahwa nilai signifikansi (Sig) dari output di atas, diperoleh nilai Deviation from Linearity Sig. adalah nilai 0,829 lebih besar dari 0.05. maka dapat disimpulkan bahwa ada pengaruh yang signifikan antara variabel gaya kepemimpinan (X) terhadap variabel kedisiplinan guru (Y).

\section{Pengujian Hipotesis}

Berdasarakan pradigma tersebut terlihat bahwa, untuk judul penelitian yang terdiri atas satu variabel independen dan satu dependen, terdapat dua rumusan masalah deskriptif. Dengan demikian juga terdapat dua hipotesis deskriptif. Teknik statistik yang ada pada tabel. 14 dapat digunakan dengan menghitung koefisien determinasi. Koefisien determinasi dihitung mengkuadratnya $100 \%$ koefisien diterminasi (penentu) dinyatakan dalam persen. Jadi untuk judul pengaruh gaya kepemimpinan terhadap kedisiplinan guru pertama-tama dihitung koefisien korelasinya, minsalnya ditemukan korelasi positif dan signifikan antara gaya kepemimpinan dengan kedisiplinan guru sebesar 0,82 . Hal itu berarti koefisien determinasi nya $=0,82^{2}=0,41$. Jadi dapat disimpulkan bahwa varians yang terjadi pada variabel kedisiplinan guru $41 \%$ dapat dijelaskan melaui varians yang terjadi pada variabel gaya kepemimpinan atau dapat dinyatakan bahwa pengaruh gaya kepemimpinan terhadap kedisiplinan guru sama dengan $41 \%$, sedangkan sisanya 59\% ditentukan oleh faktor diluar variabel gaya kepemimpinan seperti kesadaran diri, rasa terbebani dan lain-lain.

Penelitian ini bertujuan untuk mengetahui apakah ada pengaruh gaya kepemimpinan kepala sekolah terhadap kedisiplinan guru di Sekolah Menengah Kejuruan Negeri 1 Tanah Sepengggal Kabupaten Bungo.Setelah menganalisis instrumen yang dibagikan kepada guru 
yang berjumlah 30 orang baik itu guru PNS maupun guru honorer di SMK N 1 Tanah Sepenggal. Pengujian ini menggunakan uji prasyarat analisis.

Berdasarkan hasil analisis regresi linieritas maka didapat hasil signifikansi output sebesar 0,829 dengan taraf signifikansi $5 \%$ atau nilai sig 0,05 dengan jumlah sampel (N) 30. Maka $\mathrm{H}_{\mathrm{o}}$ diterima dan $\mathrm{H}_{1}$ ditolak yang berarti terdapat pengaruh antara gaya kepemimpinan kepala sekolah terhadap kedisiplinan guru di SMK Negeri 1 Tanah Sepenggal. Hal ini menunjukkan apabila gaya kepemimpinan seorang kepala sekolah baik maka kedisiplinan guru akan meningkat. Dilihat dari hasil peneilitian menunjukkan bahwa gaya kepemimpinan terhadap kedisiplina guru terdapat pengaruh yang positif, dengan nilai koefisien diterminasi sebesar 0,829 yang menyatakan tingkat kualifikasi sangat tinggi.

Kepemimpinan kepala sekolah sangat berpengaruh dalam meningkatkan kedisiplinan guru. Kepala sekolah yang otoriter akan membuat guru terpaksa menjalankan tugasnya sehingga proses belajar mengajar menjadi tidak nyaman bagi guru dan siswa. Demikian halnya dengan guru sebagai salah satu faktor yang mempunyai peranan penting dalam pencapaian keberhasilan dalam proses belajar mengajar. Guru harus mempunyai kedisiplinan yang baik dalam melaksanakan tugasnya. Kedisiplinan yang baik dapat diartikan dengan timbulnya keinginan dan kesadaran yang tinggi dalam melaksanakan tugas-tugas tanpa adanya unsur-unsur lain yang mengakibatkan guru menjadi terpaksa melaksanakan tugasnya, misalnya takut kepada pimpinan, ingin mendapat perhatian dan lain sebagainya. Apabila kedisiplinan seperti ini yang muncul dalam diri seorang guru maka dia akan melepas tanggung jawabnya ketika kepala sekolah tidak berada di sekolah minsalkan kepala sekolah pergi untuk pmengikuti pelatihan yang diselenggarakan oleh pemerintah maka secara otomatis guru tidak akan masuk kelas tepat waktu dan mungkin guru akan duduk di kantor dengan santai .

Selain itu seorang guru harus sesuai dengan samboyan Tut Wuri Handayani, seorang guru harus memerikan dorongan dan arahan maka guru disini lebih cenderung menjadi keteladanan kepada 
peserta didik yang diberi kesempatan untuk berjalan sendiri, dan tidak terus menerus dicampuri, diperintah atau dipaksa, sehingga untuk menghasilkan peserta didik yang berkualitas salah satu faktor utamanya adalah kedisiplinan guru di sekolah karena hal inilah yang akan menjadi contoh buat para peserta didik di sekolah. Kedisiplinan merupakan hal yang sangat penting, dalam rangka pencapaian pendidikan yang baik maka yang perlu diperhatikan adalah bagaimana mendisiplinkan guru karena guru merupakan pelaku utama dalam dunia pendidikan. Maka dari itu peran penting dari kepala sekolah untuk mendisiplinkan guru baik itu waktu, kerapian dan sebagainya, pembawaan dan cara kepala sekolah sangat berpengaruh dan meningkatkan kedisiplinan seorang guru seorang pemimpin mencerminkan bagaimana anggotanya.

\section{PENUTUP}

Dari hasil penelitian yang telah dilaksanakan oleh peneliti di Sekolah Menengah Kejuruan Negeri 1 Tanah Sepenggal Kabupaten Bungo, dapat disimpulkan bahwa variabel gaya kepemimpinan (X) berpengaruh pada variabel (Y) dan pada pengujian linieritas di program SPSS maka didapat perhitungngan signifikansi sebesar 0,829 dengan uji koefisien determinasi hanya sebesar $41 \%$ dan sisanya dipengaruhi oleh faktor lain diluar variabel penelitian.

Berdasarkan hasil uji liniertas regresi diketahui bahwa $F_{\text {hitung }}=$ 2,69 dan $F_{\text {tabel }}=2,19$ dengan taraf signifikansi 5\% maka jika

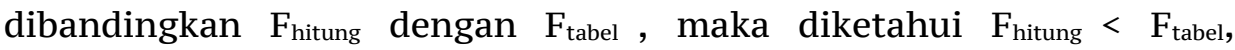
sehingga dapat disimpulkan bahwa ada pengaruh yang signifikan antara gaya kepemimpinan dengan kedisiplinan guru di Sekolah Menengah Kejuruan Negeri 1 Tanah Sepenggal Kabupaten Bungo. 


\section{Daftar Pustaka}

Kementrian Agama RI, Al-qur'an dan Terjemahannya. Jawa Tengah: Penerbit Madina, 2016.

Ating Somantri dan Sambas Ali Muhidin, Aplikasi Statistika Dalam Penelitian. Bandung: CV Pustaka Setia, 2006.

E. Mulyasa, Manajemen Berbasis Sekolah Konsep Strategi dan Implementasi. Bandung: Remaja Rosdakarya, 2012.

Hamka Abdul Aziz, Karakter Guru Profesional. Jakarata: PT AlMawardi Prima, 2016.

Imam Abdul Fida Isma'il Ibnu Kasit Ad-Dimasyqi, Tafsir Ibnu Katsir, terjemahan. Bahrun Abu Bakar. Bandung: Sinar Baru Algesindo, 2009.

Jamil Suprihatiningrum, Guru Profesional. Yogyakarta: Ar-Ruzz Media, 2016.

Jason A. Colquitt, J. Lepine, Michael J. Wessom, Organizational Behavior Improving Performance and Commitment in the Workplace. USA: Mc.Graw-Hill Education, 2015.

Marno dan Triyo Supriyatno, Manajemen dan Kepemimpinan Pendidikan Islam. Bandung: PT Refika Aditama, 2008.

Misbahuddin dan Iqbal Hasan, Analisis Data Penelitian dengan Statistik. Jakarta: PT Bumi Aksara, 2013.

Moersetyo Rahadi dan Sudrajat Subana, Statistika Pendidikan. Bandung: CV Pustaka Setia, 2000.

Peraturan Mentri Pendidikan Nasional No 20 Tahun 2003 Tentang Pendidik dan Tenaga Kependidikan. Jakarta: Lembaran Negara RI Tahun 2003.

Sugiyono, Metode Penelitian Kuantitatif, Kualitatif dan $R \& D$. Bandung: Alfabeta, 2013. 
Suwatno dan Donni Juni Priansa, Manajemen SDM dalam Organisasi Publikasi dan Bisnis. Bandung: Alfabeta, 2013.

Tarbani Rusyan, Pendidikan Budi Pekerti. Bandung: PT Sinergi Pustaka Indonesia, 2006.

Tikno Lensufiie, Leadership untuk Profesional dan Mahasiswa. Jakarta: Erlangga,2010.

UU Republik Indonesia No. 14 Tahun 2004, “Guru dan Dosen." http://UU-nomor-14-tahun-2004-ttg-guru-dan-dosenpdf.Diakses pada tanggal 2 Maret 2019.

Wahyudi, Kepemimpinan Kepala Sekolah Dalam Organisasi Pembelajar. Pontianak: Alfabeta, 2009. 